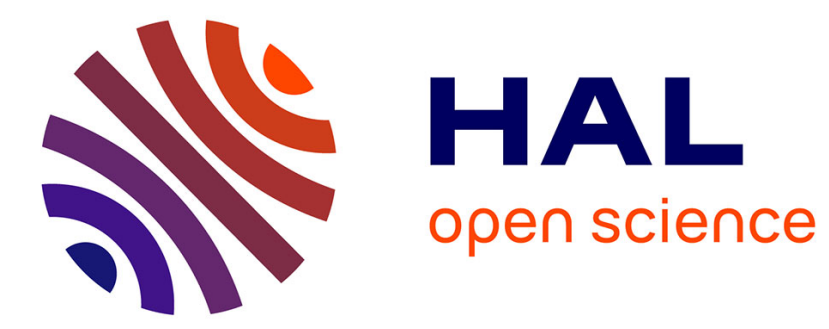

\title{
SPECIFIC HEAT OF THE TWO-DIMENSIONAL SPIN-1/2 HEISENBERG FERROMAGNET
}

\author{
P. Bloembergen, K. Tan, F. Lefevre, A. Bleyendaal
}

\section{To cite this version:}

P. Bloembergen, K. Tan, F. Lefevre, A. Bleyendaal. SPECIFIC HEAT OF THE TWODIMENSIONAL SPIN-1/2 HEISENBERG FERROMAGNET. Journal de Physique Colloques, 1971, 32 (C1), pp.C1-878-C1-879. 10.1051/jphyscol:19711310 . jpa-00214342

\section{HAL Id: jpa-00214342 https://hal.science/jpa-00214342}

Submitted on 1 Jan 1971

HAL is a multi-disciplinary open access archive for the deposit and dissemination of scientific research documents, whether they are published or not. The documents may come from teaching and research institutions in France or abroad, or from public or private research centers.
L'archive ouverte pluridisciplinaire HAL, est destinée au dépôt et à la diffusion de documents scientifiques de niveau recherche, publiés ou non, émanant des établissements d'enseignement et de recherche français ou étrangers, des laboratoires publics ou privés. 


\title{
PHÉNOMENES CRITIOUES DANS LES SYSTEMES MAGNÉTIOUES A UNE OU DEUX DIMENSIONS
}

\section{SPECIFIC HEAT OF THE TWO-DIMENSIONAL SPIN $-\frac{1}{2}$ HEISENBERG FERROMAGNET}

\author{
BLOEMBERGEN (P.), TAN (K. G.), LEFEVRE (F. H. J.), BLEYENDAAL (A. H. M.) \\ Natuurkundig Laboratorium der Universiteit van Amsterdam, the Netherlands
}

\begin{abstract}
Résumé. - On rend compte de mesures de capacité calorifique sur les composés du cuivre, $\mathrm{Cu}\left(\mathrm{C}_{n} \mathrm{H}_{2 n+1} \mathrm{NH}_{3}\right)_{2} \mathrm{Cl}_{4}$ et $\mathrm{Cu}\left(\mathrm{C}_{n} \mathrm{H}_{2 n+1} \mathrm{NH}_{3}\right)_{2} \mathrm{Br}_{4}$, avec $n$ variant de 1 à 5 . On donne la courbe de chaleur spécifique du ferromagnétisme d'Heisenberg quadratique ; cependant, la séparation entre les contributions d'origine magnétique et celles provenant du réseau a constitué un problème compliqué.

La courbe résultante fait apparaître un maximum large de $C_{\max } / \mathbf{R}=0,36$ à $k T_{\max } / J=1,1$. Aux environs de $k T_{\mathrm{c}} / J=0,45$, on trouve de très petites anomalies du type $\lambda$, dont la quantité de chaleur décrốt quand $n$ croît.
\end{abstract}

Abstract. - Heat capacity experiments are reported on the copper compounds $\mathrm{Cu}\left(\mathrm{C}_{n} \mathrm{H}_{2 n+1} \mathrm{NH}_{3}\right)_{2} \mathrm{Cl}_{4}$ and $\mathrm{Cu}\left(\mathrm{C}_{n} \mathrm{H}_{2 n+1} \mathrm{NH}_{3}\right)_{2} \mathrm{Br}_{4}$ with $n$ varying from 1 to 5 . A curve for the specific heat of the quadratic Heisenberg ferromagnet is produced ; however, the separation of the magnetic and lattice contributions has been a complicated problem.

The resultant curve shows a broad maximum of $C_{\max } / R=0.36$ at $k T_{\max } / J=1.1$. Very small $\hat{\lambda}$-type anomalies, the heat content of which decreases with increasing $n$ are found around $k T_{\mathrm{c}} / J=0.45$.

In the series $\mathrm{Cu}\left(\mathrm{C}_{n} \mathrm{H}_{2 n+1} \mathrm{NH}_{3}\right) \mathrm{Cl}_{4}$ the copper ions are arranged in planes, the separation of which can be varied from 2 to 6 times the nearest neighbour copper-copper distances by varying $n$ from 1 to 10 . The two dimensional character of the compounds thus being evident, the problem remains to what extent other deviations like that of residual anisotropy effects may change the properties with respect to those of the ideal system.

In order to be able to separate the magnetic specific heat from that of the lattice waves - which turned out to be a difficult problem - we have also studied some diamagnetic, isomorphous, $\mathrm{Cd}$ and $\mathrm{Pd}$ compounds. For these compounds no simple $\mathrm{T}^{3}$-Debye law is found even in the liquid helium temperature range. Below $10^{\circ} \mathrm{K}$ the data strongly resemble those reported in literature for other solids with pseudo-two dimensional properties, such as graphite.

Assuming that the lattice can be treated up to $10 \% \mathrm{~K}$ as an anisotropic continuous medium, we describe the specific heat in this range by a hybrid Debye function, as used originally by Tarasov [3].

$C_{2,3}=D_{2}\left(\theta_{2} / T\right)-\left(\theta_{3} / \theta_{2}\right)^{2}\left[D_{2}\left(\theta_{3} / T\right)-D_{3}\left(\theta_{3} / T\right)\right]$

$D_{2}$ and $D_{3}$ are Debye functions for two and three dimensions, $\theta_{2}$ and $\theta_{3}$ are the characteristic temperatures determined by the elastic constants of the intra- and inter-layer bonds, respectively.

The results for the diamagnetic compounds between 10 and $40^{\circ} \mathrm{K}$ can be described reasonably well by adding two Einstein terms to the Debye function, taking the Einstein temperatures $\theta^{\mathrm{E}}$ and the amplitudes, $n^{\mathbf{E}}$, as adjustable parameters. The $\theta^{\mathbf{E}}$ values are rather low, which may possibly be connected with the occurrence of low lying narrow optical bands due to the presence of the flexible $\mathrm{C}_{n} \mathrm{H}_{2 n+1} \mathrm{NH}_{3}^{+}$ions. In total 6 parameters are needed to describe the lattice heat capacity between 1 and $40 \circ \mathrm{K}$, viz., $\theta_{2}, \theta_{3}, n_{1}^{\mathrm{E}}$, $n_{2}^{\mathrm{E}}, \theta_{1}^{\mathrm{E}}$, and $\theta_{2}^{\mathrm{E}}$.

The corresponding parameters for the copper compounds have been obtained as follows :

1. The sum of lattice and magnetic energies and entropies is matched to the experimental values obtained by integrating the specific heat curve (using $S_{\text {magn }}=\mathrm{R} \ln 2$ and for a square lattice with $S=\frac{1}{2}$, $U_{\text {magn }}=\mathrm{R} J / \mathrm{k}$ ).

2. At low temperatures $\left(T<0.4 T_{\mathrm{C}}\right) C_{\text {magn }}$ is linearly dependent on temperature and is determined (*) by the value of $J / k$, as predicted by simple spin wave theory and as found experimentally below $1{ }^{\circ} \mathrm{K}$ by Colpa [5].

3. At high temperatures $\left(T \geqslant 2.5 T_{\mathrm{C}}\right)$ the magnetic specific heat curve has to be connected to results from high temperature series expansions by Baker e. a. [6], the magnetic specific heat, energy and entropy above this temperature being fully determined by the value of $J / k$.

4. The amplitude of the Einstein contributions, $n_{1}^{\mathrm{E}}$ and $n_{2}^{\mathrm{E}}$ in the present approach, are taken equal to those for the corresponding diamagnetic compounds. With the requirement 1 to 4 the characteristic temperatures $\theta_{1}^{\mathrm{E}}$, and $\theta_{2}^{\mathrm{E}}$ are determined and so is the lattice contribution as a whole.

The results for the chlorides with $n=1$ and $n=3$, obtained by subtraction of the lattice contribution, are shown in figure 1 together with those for the Heisenberg chain antiferromagnet [7] and the B. C. C. ferromagnet [8]. The difference between the two experimental curves is sufficiently small to give a rather accurate curve for the S. Q. magnet. The resemblance of this curve to that predicted theoretically for a chain antiferromagnet, for which there is no doubt that there is no phase transition, is striking.

The experiments show very weak $\lambda$-type anomalies around $k T / J=0.45$, as indicated by the arrows in the figure. In view of the fact that the linear dependence, observed down to temperatures below $10^{-2} \mathrm{~J} / \mathrm{k}$ agrees with that expected for the ideal system and the heat content of the $\lambda$-peak is extremely small, $\left(U_{\text {peak }} / U_{\text {total }} \simeq 10^{-3}\right)$ our experimental curve may be considered as representative for the ideal $S$. $Q$. Heisenberg ferromagnet.

In table I we compare the characteristics of the curve in figure 1 with that of a few other simple magne- 
TABLE I

Characteristics of simple magnetic systems
Heisenberg, $S=\frac{1}{2}$
Chain ferromagnet
Chain antiferromagnet
S. Q. antiferromagnet
S. Q. ferromagnet
B. C. C. ferromagnet

$\begin{array}{ll}k T_{\max } / J & C_{\max } / R \\ 0 . \overline{7} & \overline{0.134} \\ 0.962 & 0.35 \\ 1.25 & 0.4 \\ 1.1 & 0.36 \\ & >14\end{array}$

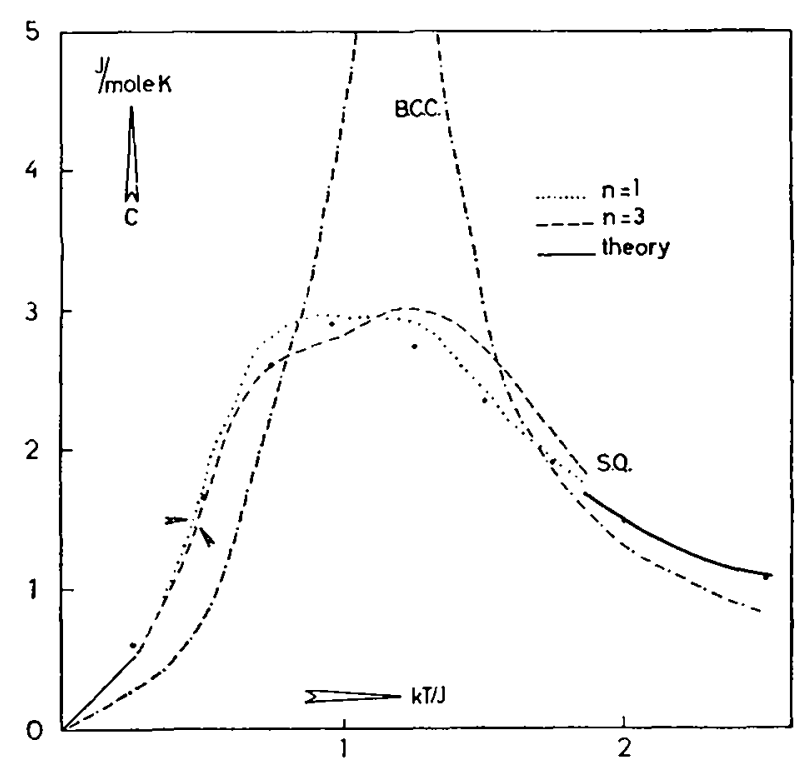

Fig. 1. - The magnetic heat of two compounds of the series $\mathrm{Cu}\left(\mathrm{C}_{n} \mathrm{H}_{2 n+1} \mathrm{NH}_{3}\right)_{2} \mathrm{Cl}_{4}$, which may represent the quadratic $S=\frac{1}{2}$ Heisenberg ferromagnet. Also shown are the B. C. C. ferromagnet, and the $S=\frac{1}{2}$ antiferromagnetic chain (heavy black dots).

tic systems; data for the S. Q. spin $\frac{1}{2}$ Heisenberg antiferromagnet are taken from experiments on the radical DPAN by Duffy e. a. [9]. The values for $U_{\mathrm{C}} / U_{\text {tot }}$ and $S_{\mathrm{C}} / S_{\text {tot }}$ in our case correspond to the fraction of energy and entropy removed below $T_{\mathrm{C}}$ where $T_{\mathrm{C}}$ is considered to approximate that temperature at which the susceptibility for the ideal system diverges. That this critical temperature really exists is suggested by figure 2 which plots the heat content of the $\lambda$-type anomaly versus $k T_{c} / J$ (see also Miedema's paper at this conference). The figure shows 10 points both for the chlorides and bromides with $n=1 \ldots .5$. Along the line the ratios $T_{\mathrm{c}} / \theta=k T_{\mathrm{c}} / 2 \mathrm{~J}$ and $U_{\text {peak }} / U_{\text {total }}$ increase rather regularly with decreasing interplane distance. For the bromides, the triangles in figure $2, T_{\mathrm{C}} / \theta$ and $U_{\text {peak }} / U_{\text {total }}$ are somewhat larger than for the corresponding chlorides, which seems reasonable in view of the fact that susceptibility data

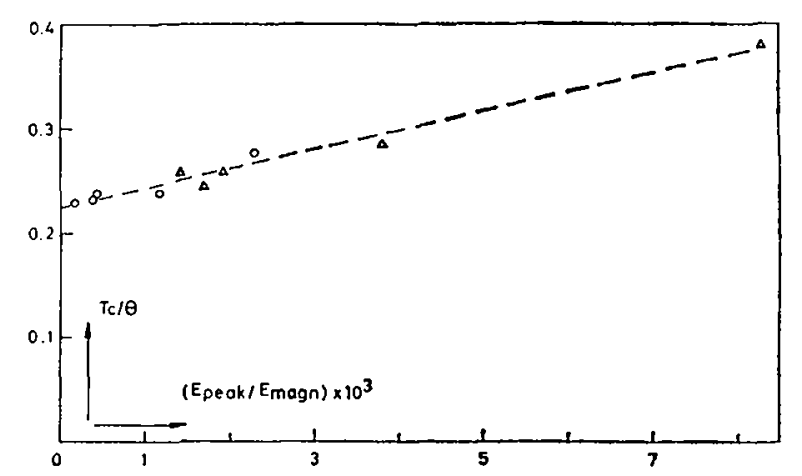

FIG. 2. - The transition temperatures of our copper compounds plotted versus the energy content of the $\lambda$-type anomaly. It is suggested that this energy is a measure for the deviations of the actual crystal from the ideal $S=\frac{1}{2}$ quadratic Heisenberg ferromagnet.

point to a somewhat larger (exchange) anisotropy for the bromides.

One is inclined to extrapolate the straight line in figure 2 towards a disappearing heat capacity anomaly and to define the $T_{\mathrm{c}} / \theta$ value thus obtained as representative for the ideal system. This extrapolation, as a matter of fact, assumes that the range of deviations from the ideal system is sufficiently large to permit an extrapolation.

Transition to long range order seems to occur always at the temperature at which the susceptibility tends to become infinite. Long range dipole-dipole interactions may have something to do with this and in that way the finiteness of the experimental system will play a role of importance.

Acknowledgements. - This work is part of the research program of the "Stichting voor Fundamenteel Onderzoek der Materie " and was made possible by financial support from the "Nederlandse Organisatie voor Zuiver Wetenschappelijk Onderzoek ».

(*) Certain assumptions with regard to the lattice heat capacity in this temperature range enable us to derive $J / k$ values independently. As the values obtained from high temperature $\chi$ data [4] may be considered as more accurate we rely on them in the present discussion.

\section{References}

[1] Stanley (H. E.) and Kaplan (T. A.), Phys, Rev. Letters, 1966, 17, 913.

[2] Miedema (A. R.), this conference.

[3] Tarasov (V. V.), New problems in the physics of glass, Jerusalem 1963.

[4] De Jongh (L. J.) and VAN Amstel (W.), this conference.

[5] Colpa (J. H.), to be published in Physica.
[6] Baker (G. A.), Gilbert (H. E.), Eve (J.) and RushBROOKE (G. S.), Phys. Letters, 1967, 25 A, 3. [7] Bonner (J. C.) and Fisher (M. E.), Phys. Rev., 1964, 135,640 .

[8] Miedema (A. R.), Wielinga (R. F.) and Huiskamp (W. J.), Physica, 1965, 31, 1585.

[9] Duffy (W. J. J), STrandburg (J. L.) and Deck (J. F.), Phys. Rev., 1969, 183, 567. 